\title{
Desenvolvimento vegetativo inicial de porta-enxertos cítricos cultivados em diferentes substratos
}

\author{
Vegetative development of citrus rootstocks seedlings cultivated in different growing media
}

\author{
Gilmar Schäfer $^{1 *}$ Paulo Vitor Dutra de Souza ${ }^{1}$ Otto Carlos Koller ${ }^{1}$ \\ Sérgio Francisco Schwarz ${ }^{1}$
}

\section{RESUMO}

Com o objetivo de avaliar o desenvolvimento vegetativo de porta-enxertos cítricos em diferentes substratos de cultivo, foi instalado um experimento, conduzido em casa de vegetação, com sistema de irrigação por microaspersão, na Estação Experimental Agronômica da UFRGS, a partir do dia 27 de setembro de 2001. O delineamento experimental adotado foi em blocos ao acaso, em esquema de parcela subdividida, com quatro repetições. Nas parcelas principais, foram testados substratos, sendo dois encontrados no comércio especializado em horticultura (Comercial 1 e 2) e uma mistura (turfa mais casca de arroz carbonizada - na proporção de 1:1 em v:v). Nas subparcelas, foram testados quatro porta-enxertos cítricos ("Trifoliata", Citrange "C13", Citrange "C37" e Limoeiro "Cravo"). Os principais resultados demonstram que é possível produzir porta-enxertos, na fase de sementeira, com bom tamanho e desenvolvimento radicular, com 120 dias após a semeadura, e que as características químicas dos substratos são determinantes para o desenvolvimento adequado dos portaenxertos, sendo prejudicial a salinidade elevada.

Palavras-chave: cultivo protegido, propagação, casa de vegetação.

\section{ABSTRACT}

The present study was aimed at evaluating the vegetative development of citrus seedlings rootstocks cultivated in different substrates. The experiment was installed at greenhouse conditions in the Estação Experimental Agronômica UFRGS, from September 27, 2001. The experimental design used was that of randomized blocks, in a split plot scheme, with four replications. In the main parcels were tested substrate, two commercial, found in the specialized trade in horticulture and a mixture. In the sub parcels were tested four citrus rootstock (Trifoliate orange, 'C13' Citrange, 'C37' Citrange and 'Rangpur' Lime). The main results showing that is possible to produce citrus rootstock seedlings with good size and root development, with 120 days after sowing. The chemistries characteristics of the substrate are decisive for the appropriate development of the rootstock seedlings, being harmful the high salinity.

Key words: protected environment, propagation, greenhouse.

\section{INTRODUÇÃO}

No Brasil, na década de 90 , cerca de $80 \%$ dos pomares eram constituídos pelo porta-enxerto limoeiro "Cravo" (Citrus limonia Osbeck.), pela sua característica de induzir vigor, maior tolerância ao estresse hídrico e alta produtividade. Entretanto, este está sendo substituído, principalmente por problemas fitossanitários, como o da morte súbita dos citros. Já, no Rio Grande do Sul, a estimativa é de que $90 \%$ das mudas estão enxertadas sobre Poncirus trifoliata (SCHÄFER \& DORNELLES, 2000). Esta falta de diversificação de porta-enxertos poderá acarretar em vulnerabilidade, com o aparecimento de novas moléstias, como ocorrido no caso da tristeza, na década de 40, e, mais recentemente, com a morte súbita dos citros.

Nos últimos anos, devido à ocorrência de problemas fitossanitários associados ao solo, como nematóides, gomose e bacterioses em pomares cítricos recém-implantados, tem sido despertado um maior interesse na produção de mudas envasadas (CARVALHO \& SOUZA, 1996). Nos sistemas de produção de mudas de citros em ambiente protegido,

${ }^{1}$ Departamento de Horticultura e Silvicultura da Faculdade de Agronomia da Universidade Federal do Rio Grande do Sul (UFRGS). Av. Bento Gonçalves, 7712, 91501-970, Porto Alegre, RS, Brasil. E-mail: gilmarschafer@ hotmail.com, pvdsouza@ufrgs.br, ockoller@ufrgs.bre schwarz@ufrgs.br. *Autor para correspondência. 
pode-se evitar com maior facilidade a contaminação de plantas por moléstias. A produção divide-se em duas fases: uma de sementeira, em que são utilizados tubetes ou bandejas de isopor e, posteriormente, a formação no viveiro em vasos (citropotes) ou sacos plásticos; sendo ambas as fases realizadas em casa de vegetação telada (CARVALHO \& SOUZA, 1996). Neste tipo de cultivo, a produção de mudas é realizada com a utilização de substratos livres de solo, o que possibilita a obtenção de mudas de alta qualidade, com sistema radicular mais volumoso, o que acelera o pegamento e a retomada do crescimento no pomar (TEÓFILO SOBRINHO, 1991).

Em sistemas de produção de mudas de citros envasadas, já utilizados em vários países, inclusive no Brasil, no Estado de São Paulo, pode-se produzir a muda de 10 a 15 meses após a semeadura (CARVALHO et al., 2005). Atualmente, o sistema de produção de mudas cítricas, a campo, no Rio Grande do Sul, desde a sementeira até a comercialização, leva 36 meses. Com a utilização de cultivo em ambiente protegido e recipientes adequados, este tempo pode ser reduzido em até $50 \%$ (JO ÃO, 1999). O desenvolvimento de plantas hortícolas em estufas com o uso de bandejas multicelulares, tubetes ou sacos plásticos demanda a utilização de substratos adequados para que se tenha sucesso na atividade. O conhecimento de suas características químicas (pH, CTC e TTSS) e físicas (PT, EA, densidade e retenção de água) é essencial para o sucesso do empreendimento (FERMINO, 1996).

Já em 1998 a bibliografia citava que, no mercado nacional, estavam disponíveis diferentes substratos, obtidos a partir de misturas de diferentes materiais, indistintamente recomendados a um grande número de espécies, cujas formulações e características eram pouco conhecidas e cujos desempenhos, como meio de cultivo, poderiam ser irregulares (MENEZES JÚNIOR \& FERNANDES, 1998). Atualmente, existem grandes empresas produtoras de substrato, muitos deles específicos para diferentes fases de produção de mudas para grandes culturas, como ocorre com a produção de mudas cítricas. Entretanto, a preocupação com a qualidade dos materiais, conforme discutido por MENEZES JÚNIOR \& FERNANDES (1998), ainda deve ser constante.

Existe um grande interesse na diminuição do tempo para a formação da muda cítrica e no controle das condições fitossanitárias, uma vez que isto gera benefícios, tanto na própria comercialização da muda como no futuro pomar a ser instalado. Portanto, este trabalho tem por objetivo avaliar o desenvolvimento vegetativo inicial de diferentes porta-enxertos cítricos cultivados em diversos substratos, mantidos em tubetes plásticos, sob condições de casa-devegetação.

\section{MATERIAL E MÉTODOS}

O experimento foi conduzido em casa de vegetação da Estação Experimental Agronômica da Universidade Federal do Rio Grande do Sul (EEA/ UFRGS), situada em Eldorado do Sul, RS, a partir do dia 27 de setembro de 2001 .

O delineamento experimental adotado foi em blocos ao acaso, em esquema de parcela subdividida, com quatro repetições. Nas parcelas principais, testouse substratos, sendo dois comerciais, encontrados no comércio especializado em horticultura: a) Comercial 1 - substrato Rendimax Citrus ${ }^{\circledR}$ (fabricante Eucatex ${ }^{\circledR}$ substrato composto de cascas processadas e enriquecidas, vermiculita expandida, perlita expandida e turfa processada e enriquecida); b) Comercial 2 substrato Mecplant Citrus $1^{\circledR}$ (fabricante Wolff Klabin Mec Prec ${ }^{\circledR}$ - composição não especificada); e c) Mistura 1 - mistura de substrato comercial a base de turfa (Turfa Fértil $^{\circledR}$ - turfa preta) mais casca de arroz carbonizada (na proporção de 1:1, em v:v). Nas subparcelas, foram testados quatro porta-enxertos cítricos: a) "Trifoliata" - Poncirus trifoliata (L.) Raf.; b) citrange "C13" - P trifoliata $\boldsymbol{x}$ Citrus sinensis (L.) Osbeck; c) citrange "C37" - P. trifoliata x C. sinensis (L.) Osbeck e, d) limoeiro "Cravo" - C. limonia Osbeck. A subparcela foi constituída de 20 tubetes, totalizando 80 tubetes por parcela principal e 240 por bloco.

A semeadura foi realizada em tubetes cônicos de polietileno preto (capacidade de $120 \mathrm{~cm}^{3}$ ), vazados na parte basal, fixados em bancadas metálicas a um metro do solo. Foi colocada uma semente por tubete, à profundidade de um a dois cm, dependendo do tamanho desta. As irrigações foram feitas mediante sistema de microaspersão, com temporizador, por dez minutos, duas vezes ao dia. Não houve complementação de luz e de nutrientes nesse experimento.

As seguintes características foram avaliadas: a) determinação do vigor, através de: comprimento da parte aérea, medida do colo até o ápice da haste, em cm; diâmetro da haste, ao nível do colo, em mm; área foliar por plântula, em cm² , medida através da passagem das folhas por um medidor de área foliar de marca LI-Cor, modelo LI - 3100; matéria seca da raiz, parte aérea e total (raiz + parte aérea), em gramas, obtida pela secagem em estufa, com temperatura de $65^{\circ} \mathrm{C}$, até peso constante; b) caracterização química dos substratos antes do cultivo e determinação de $\mathrm{N}$ (total), $\mathrm{P}, \mathrm{K}, \mathrm{Ca}$ e Mg na matéria seca da parte aérea, segundo 
metodologia descrita por TEDESCO et al. (1995), realizadas no Laboratório de Solos e Tecidos do Departamento de Solos da UFRGS. Também determinou-se os valores de $\mathrm{pH}$ e de carbono orgânico (C.O.) e o teor total de sais solúveis (TTSS), segundo metodologia proposta por RÖBER \& SCHALLER (1985) e adotada por SCHMITZ (1998); c) caracterização física dos substratos antes do cultivo, realizada no Laboratório de Análise de Substratos para Plantas do Departamento de Horticultura e Silvicultura, segundo metodologia descrita por HOFFMAN (1970) e DE BOODT \& VERDONCK, (1972); d) consistência do torrão, quando da retirada deste do tubete, atribuindose notas de 1 (raízes nuas) a 5 (torrão intacto).

As médias foram submetidas à análise de variância e comparadas pelo teste de Duncan em nível de $5 \%$ de probabilidade de erro. Para a variável crescimento em altura das plantas, no decorrer do experimento, foi realizada a análise de variância em esquema de parcela sub-subdividida e submetida à análise de regressão polinomial.

\section{RESULTADOS E DISCUSSÃO}

Não houve interação significativa entre substrato e porta-enxerto para todas as características avaliadas (Tabelas 1, 2, e 3 e Figura 1). O porta-enxerto "Trifoliata" apresentou o maior desenvolvimento em altura, atingindo aos 120 dias desde a semeadura, altura média maior que $15 \mathrm{~cm}$. Os citranges apresentaram performance intermediária, com o "C37" superior ao "C13" e o limoeiro "Cravo" com a menor altura. Observa-se, pela figura 1 , que a tendência de crescimento em altura foi linear e constante para todos os porta-enxertos estudados. Conforme já relatado por SCHÄFER (2000), o “Trifoliata" tem um crescimento inicial muito rápido, podendo atingir alturas bem superiores aos demais já na primeira semana após a germinação. Pode-se observar, na figura 1, que o "Trifoliata", já aos 56 dias após a semeadura (DAS), apresentava altura maior, mantendo-a até o final do experimento.

A altura das plantas nos diferentes substratos estudados mostrou-se significativa, apresentando diferenças de aproximadamente $40 \%$ para essa característica. Observa-se que o substrato comercial 1 proporcionou os melhores índices, seguido pela mistura 1 e, por último, pelo substrato comercial 2 (Figura 1). A diferença no desenvolvimento dos portaenxertos nos três substratos acentuou-se ao longo do tempo, sendo que aos 56 DAS todos os porta-enxertos estavam com aproximadamente $6 \mathrm{~cm}$ e, no final do cultivo, as diferenças entre o substrato 2 e os demais chegou a aproximadamente $4 \mathrm{~cm}$.

Um fator importante no desenvolvimento do porta-enxerto é o diâmetro da haste, porque o maior desenvolvimento em diâmetro pode antecipar o tempo de enxertia. Neste trabalho, verificou-se diferenças significativas entre os porta-enxertos estudados para essa característica, com o citrange "C37" apresentando os melhores resultados, seguido pelo "Trifoliata" e o “C13” e, por último, o limoeiro "Cravo"(Tabela 1).

Em experimento realizado com a propagação do limoeiro "Cravo" e da tangerineira "Cleópatra" em bandejas com alvéolos de $75 \mathrm{~cm}^{3}$, CARVALHO \& SOUZA (1996) obtiveram, aos 120 dias de cultivo,

Tabela 1 - Diâmetro (D), área foliar (AF), número de folhas por planta (NFP), área foliar por folha (AFF), matéria seca das raízes (MSR), da parte aérea total (MAT), matéria seca total por planta (MST) e consistência do torrão (CT) de porta-enxertos cítricos, cultivados em diferentes substratos em casa de vegetação. EEA/UFRGS, Eldorado do Sul, 2001.

\begin{tabular}{|c|c|c|c|c|c|c|c|c|c|}
\hline \multirow{2}{*}{ Tratamento } & & $\mathrm{D}$ & $\mathrm{AF}$ & \multirow{2}{*}{ NFP } & $\mathrm{AFF}$ & MSR & MAT & MST & \multirow{2}{*}{ CT } \\
\hline & & $\mathrm{mm}$ & $\mathrm{cm}^{2} \mathrm{pl}^{-1}$ & & $\mathrm{~cm}^{2}$.folha ${ }^{-1}$ & --- & planta & ------ & \\
\hline \multirow{4}{*}{ Porta-enxerto } & "C37" & $2,52 \mathrm{a}^{1}$ & $34,27 \mathrm{a}$ & $10,47 \mathrm{~b}$ & $3.22 \mathrm{a}$ & $0,42 \mathrm{a}$ & $0,20 \mathrm{a}$ & $0,62 \mathrm{a}$ & $4,49 \mathrm{a}$ \\
\hline & "Trifoliata" & $2,31 \mathrm{~b}$ & $18,05 \mathrm{c}$ & $12,76 \mathrm{a}$ & $1,39 \mathrm{~b}$ & $0,34 \mathrm{~b}$ & $0,19 \mathrm{a}$ & $0,54 \mathrm{~b}$ & $4,57 \mathrm{a}$ \\
\hline & "C13" & $2,27 \mathrm{~b}$ & $27,73 \mathrm{~b}$ & $9,76 \mathrm{c}$ & $2,78 \mathrm{a}$ & $0,33 \mathrm{~b}$ & $0,20 \mathrm{a}$ & $0,53 \mathrm{~b}$ & $4,11 \mathrm{ab}$ \\
\hline & "Cravo" & $2,03 \mathrm{c}$ & $27,25 \mathrm{~b}$ & $9,16 \mathrm{~d}$ & $2,88 \mathrm{a}$ & $0,27 \mathrm{c}$ & $0,14 \mathrm{~b}$ & $0,40 \mathrm{c}$ & $3,73 \mathrm{~b}$ \\
\hline $\mathrm{CV}(\%)$ & & 3,40 & 14,92 & 3,32 & 12,08 & 9,99 & 9,21 & 9,12 & 7,03 \\
\hline \multirow{3}{*}{ Substrato } & Comercial 1 & $2.41 \mathrm{a}^{1}$ & $34,80 \mathrm{a}$ & $11,68 \mathrm{a}$ & $3,06 \mathrm{a}$ & $0,43 \mathrm{a}$ & $0,21 \mathrm{a}$ & $0,64 \mathrm{a}$ & $4,37 \mathrm{a}$ \\
\hline & Mistura 1 & $2,35 \mathrm{a}$ & $27,57 \mathrm{~b}$ & $10,88 \mathrm{a}$ & $2,62 \mathrm{~b}$ & $0,35 \mathrm{~b}$ & $0,19 \mathrm{a}$ & $0,55 \mathrm{~b}$ & $4,63 \mathrm{a}$ \\
\hline & Comercial 2 & $2,09 \mathrm{~b}$ & $18,11 \mathrm{c}$ & $9,05 \mathrm{~b}$ & $2,02 \mathrm{c}$ & $0,24 \mathrm{c}$ & $0,15 \mathrm{~b}$ & $0,39 \mathrm{c}$ & $3,68 \mathrm{~b}$ \\
\hline $\mathrm{CV}(\%)$ & & 6,90 & 25,01 & 11,62 & 16,46 & 23,79 & 22,94 & 22,45 & 15,15 \\
\hline
\end{tabular}

${ }^{1}$ Médias seguidas por letras distintas na coluna diferem entre si pelo teste de Duncan, em nível de 5\% de probabilidade de erro.

Ciência Rural, v.36, n.6, nov-dez, 2006. 
Tabela 2 - pH, teor total de sais solúveis (TTSS) e teores de nutrientes disponíveis nos substratos antes do cultivo de porta-enxertos cítricos em casa de vegetação. EEA/UFRGS, Eldorado do Sul, 2001.

\begin{tabular}{|c|c|c|c|c|c|c|c|c|c|c|c|c|}
\hline \multirow{2}{*}{ Substrato } & $\mathrm{pH}$ & & $\mathrm{P}$ & $\mathrm{K}$ & $\mathrm{Al}$ & $\mathrm{Ca}$ & $\mathrm{Mg}$ & $\mathrm{S}$ & $\mathrm{Zn}$ & $\mathrm{Cu}$ & B & $\mathrm{Mn}$ \\
\hline & \multicolumn{3}{|c|}{ 1. } & & \multicolumn{3}{|c|}{--------cmolc L ${ }^{-1}$} & \multicolumn{5}{|c|}{ 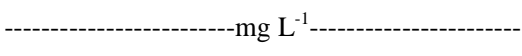 } \\
\hline Comercial 1 & 5,48 & 2,48 & 178 & 992 & 0,3 & 34 & 11 & 7,5 & 5,1 & 0,2 & 0,7 & 51 \\
\hline Comercial 2 & 4,65 & 3,14 & 978 & 2592 & 1,3 & 22 & 9,8 & 11 & 12,0 & 0,2 & 1,0 & 104 \\
\hline Mistura 1 & 6,05 & 1,81 & 142 & 863 & 0 & 26 & 12 & 11 & 4,0 & 0,2 & 1,0 & 16 \\
\hline
\end{tabular}

plantas com médias de 13,51 e 11,53cm de altura, 2,67e $1,87 \mathrm{~mm}$ de diâmetro do caule, 0,92 e $0,52 \mathrm{~g}$ planta $^{-1} \mathrm{de}$ matéria seca total, respectivamente, para os portaenxertos "Cravo" e "Cleópatra". SCHMITZ (1998), no cultivo do "Trifoliata" EEA/UFRGS em diversos substratos, encontrou valores de $14,8 \mathrm{~cm}$ de altura, $1,97 \mathrm{~mm}$ de diâmetro do colo e 14,6 folhas por planta. Além disso, SCHÄFER (2000), aos 197 dias após o cultivo de porta-enxertos em casa de vegetação, conseguiu altura de aproximadamente $10 \mathrm{~cm}$ para o "Trifoliata"; de 9cm para o "Troyer"; e de $11 \mathrm{~cm}$ para o "Swingle" e para o limoeiro "Cravo". Observa-se que, nos experimentos conduzidos pelos autores citados, ocorreu desenvolvimento similar, sendo que a tendência de maior desenvolvimento inicial do "Trifoliata" é confirmada e, principalmente, nas condições do Rio Grande do Sul, verificou-se um menor crescimento inicial do "Cravo". O comportamento apresentado pelo "C13" e "C37" evidencia que eles apresentam desempenho vegetativo igual ou superior ao de outros porta-enxertos, em ambiente protegido.

Houve diferença significativa em área foliar entre os porta-enxertos estudados (Tabela 1). O portaenxerto "C37" foi o que apresentou maiores índices, seguido do "C13" e do "Cravo" e, por último, do
"Trifoliata". Esse comportamento deveu-se ao maior crescimento do primeiro porta-enxerto que determinou a formação de maior número de folhas, sendo estas estas, ligeiramente maiores. O "Trifoliata", apesar de ter número maior de folhas, apresentou menor índice de área foliar, como conseqüência de suas características fenotípicas, pois tem folhas menores do que os demais porta-enxertos estudados.

Pode-se verificar, pelos dados da tabela 1 , que tanto o desenvolvimento em diâmetro, como os índices de área foliar, foram menores nos porta-enxertos, quando cultivados no substrato comercial 2. Este substrato induziu ao menor número de folhas por planta e à redução na área foliar por folha, o que, conseqüentemente, diminuiu o índice de área foliar, reduzindo a taxa fotossintética e gerando a diminuição de todas as características de desenvolvimento vegetativo. Os substratos comercial 1 e mistura 1 não apresentaram diferenças no diâmetro e no número de folhas emitidas por porta-enxerto; houve diferenças somente em área foliar, devido ao menor desenvolvimento da folha, como pode ser verificado nos índices de área foliar por folha.

Diversos parâmetros de matéria seca por planta estão descritos na tabela 1 . Observa-se que a

Tabela 3 - Teores de macronutrientes presentes na matéria seca aérea total de porta-enxertos cítricos, cultivados em diferentes substratos, em casa de vegetação. EEA/UFRGS, Eldorado do Sul, 2001.

\begin{tabular}{llccccc}
\hline & & \multicolumn{5}{c}{ Conteúdo nutricional g kg ${ }^{-1}$ na matéria seca aérea } \\
\cline { 3 - 6 } Tratamento & Nitrogênio & Fósforo & Potássio & Cálcio & Magnésio \\
\hline \multirow{3}{*}{ Porta-enxerto } & $10,16 \mathrm{~b}^{1}$ & 1,37 & $17,28 \mathrm{c}$ & $9,94 \mathrm{~b}$ & $3,91 \mathrm{~b}$ \\
& "C37" & $11,94 \mathrm{a}$ & 1,33 & $15,18 \mathrm{~d}$ & $8,13 \mathrm{c}$ & $3,57 \mathrm{c}$ \\
& "Crifoliata" & $12,04 \mathrm{a}$ & 1,40 & $18,45 \mathrm{~b}$ & $10,53 \mathrm{a}$ & $4,16 \mathrm{a}$ \\
CV $(\%)$ & "Cravo" & $12,46 \mathrm{a}$ & 1,47 & $20,21 \mathrm{a}$ & $9,68 \mathrm{~b}$ & $2,93 \mathrm{~d}$ \\
& & 10,84 & 12,38 & 6,19 & 5,46 & 8,06 \\
Substrato & Comercial 1 & $13,09 \mathrm{a}{ }^{1}$ & 1,43 & $18,81 \mathrm{a}$ & $11,34 \mathrm{a}$ & $2,83 \mathrm{c}$ \\
& Mistura 1 & $12,66 \mathrm{a}$ & 1,35 & $17,49 \mathrm{ab}$ & $8,78 \mathrm{~b}$ & $4,66 \mathrm{a}$ \\
CV $(\%)$ & Comercial 2 & $9,19 \mathrm{~b}$ & 1,40 & $17,05 \mathrm{~b}$ & $8,58 \mathrm{~b}$ & $3,44 \mathrm{~b}$ \\
\hline
\end{tabular}

${ }^{1}$ Médias seguidas por letras distintas na coluna diferem entre si pelo teste de Duncan, em nível de 5\% de probabilidade de erro.

Ciência Rural, v.36, n.6, nov-dez, 2006. 


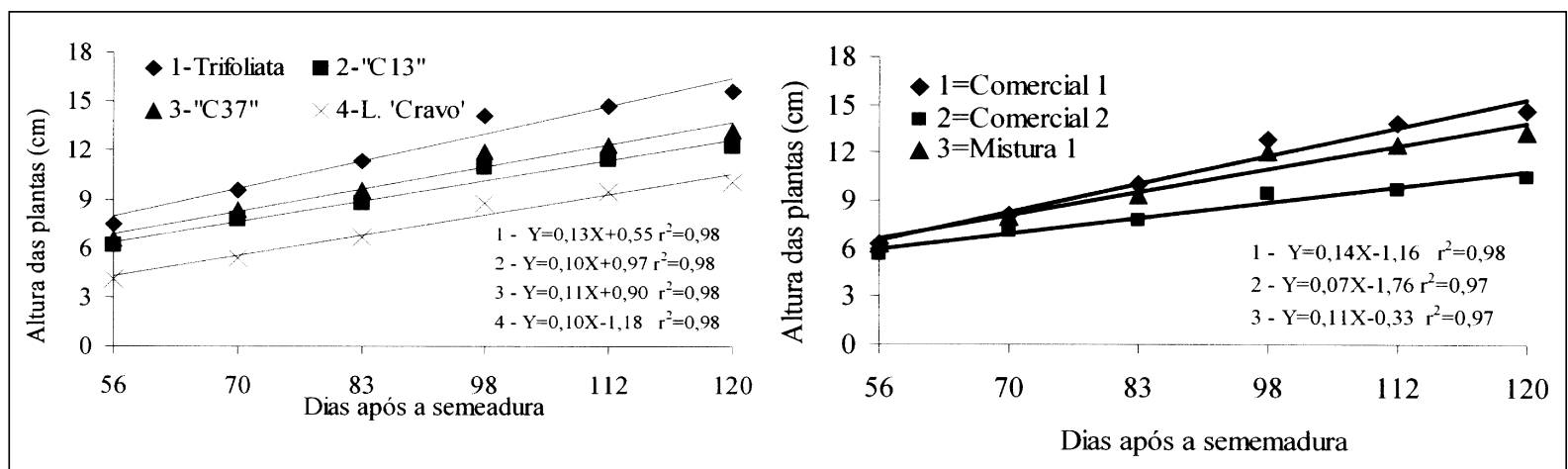

Figura 1 - Curvas de crescimento, em altura, de porta-enxertos cítricos cultivados em diferentes substratos até os 120 dias após a semeadura. EEA/UFRGS, Eldorado do Sul, RS, 2001.

altura, o diâmetro e os índices de área foliar tiveram reflexo direto no acúmulo de matéria seca dos portaenxertos nos diferentes substratos de cultivo, indicando que o Comercial 2 proporcionou os piores índices, com $64 \%$ a menos de acúmulo que o Comercial 1 , que apresentou os melhores resultados. $\mathrm{O}$ substrato mistura 1 apresentou, em geral, matéria seca intermediária aos demais. Alterações no sistema radicular, principalmente na sua distribuição e no seu volume, podem alterar a eficiência de absorção de água e de nutrientes, diminuindo, assim, o seu desenvolvimento, o que provavelmente ocorreu com os porta-enxertos cultivados no substrato comercial 2.

Uma característica importante, e que é determinante na repicagem, é a consistência do torrão, pois um dos objetivos do cultivo em tubetes é a repicagem com sistema radicular intacto, envolvido em torrão, o que ameniza o estresse da repicagem e favorece o pegamento das plântulas. Essa característica está diretamente relacionada ao desenvolvimento do sistema radicular, pois, observando-se os valores da tabela 1, verifica-se que o substrato comercial 2 apresentou valores significativamente menores de consistência de torrão, diretamente relacionado com o desenvolvimento radicular. Observa-se que quanto menor o desenvolvimento de raízes secundárias, como é o caso do limoeiro "Cravo", menor é a consistência do torrão, podendo diminuir o pegamento e o crescimento na fase seguinte à repicagem.

Como aconteceu nas demais características de desenvolvimento vegetativo, o acúmulo de matéria seca entre os porta-enxertos diferiu significativamente, sendo que o "C37" apresentou os maiores índices de matéria seca total, seguido pelo "Trifoliata" e pelo "C13" e, por último, pelo "Cravo". A maior área foliar desse porta-enxerto deve ter sido o fator determinante do maior acúmulo de matéria seca da parte aérea total.
Os resultados apresentados em termos de matéria seca são superiores aos resultados de SCHÄFER (2000), que descreve ganhos de até $0,44 \mathrm{~g}$ planta-1 na matéria seca total de porta-enxertos cultivados em diferentes substratos, aos 197 dias após a semeadura. Já o porta-enxerto "Trifoliata" apresentou resultados similares de acúmulo de matéria seca de raízes e da parte aérea total aos encontrados por SCHMITZ (1998); entretanto, com a antecipação de aproximadamente 40 dias.

A partir dos dados apresentados anteriormente, pode-se verificar que existem diferenças significativas no desenvolvimento vegetativo dos porta-enxertos e que híbridos de "Trifoliata", selecionados no Rio Grande do Sul, podem apresentar desempenho melhor do que porta-enxertos tradicionalmente usados.

Na figura 2, estão descritas as principais características físicas dos substratos antes do cultivo. O Valor "Referência" refere-se aos valores referenciais para um substrato de cultivo (SCHMITZ, 1998). Observa-se que a quantidade de sólidos presentes nos substratos pode ser considerada adequada, indicando valor não superior a $15 \%$, considerado como adequado (KÄMPF, 2000). Já os valores de espaço de aeração foram bem maiores que os considerados como referência, diminuindo a disponibilidade de água à planta (água facilmente disponível e água tamponante). A água remanescente no substrato mistura 1 encontrase perto do valor de referência; já, para os substratos comerciais, o seu valor está bem acima.

Apesar das diferenças físicas, o desempenho diferenciado proporcionado pelos substratos é explicado principalmente por suas características químicas. O substrato comercial 2 apresentava TTSS elevado (Tabela 2), inclusive causando sintomas de toxicidez aos porta-enxertos 


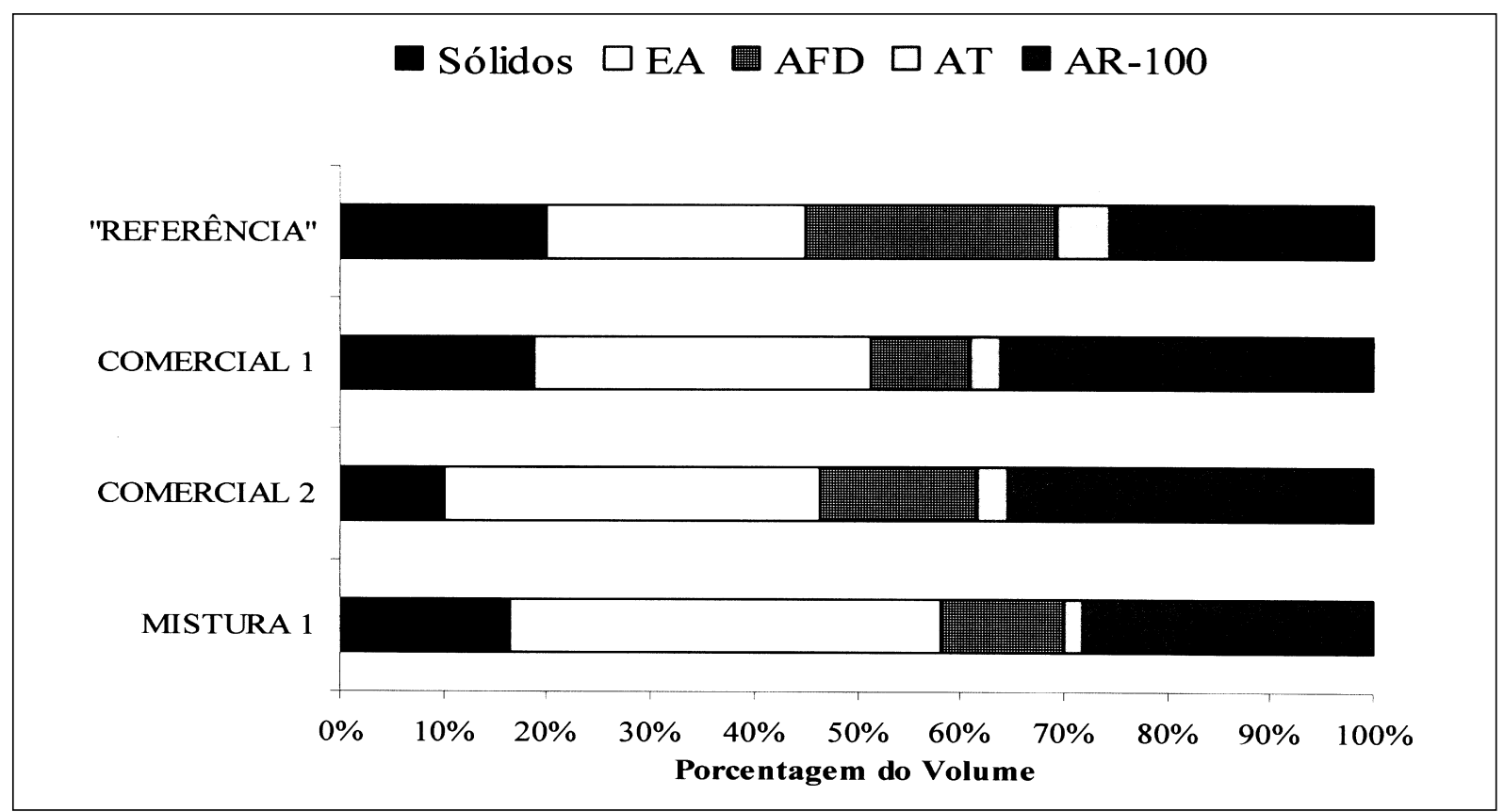

Figura 2 - Características físicas dos substratos relativas à fração do volume ocupada por sólidos, ao espaço de aeração (EA), à água facilmente disponível (AFD), à água tamponante (AT) e à água remanescente ao potencial de -100hPa (AR-100). O valor de "REFERÊNCIA" refere-se à média dos valores descrita por vários autores, conforme relata SCHMITZ (1998).

testados, o que não ocorreu com os outros dois substratos.

A salinidade pode ser considerada como um dos problemas mais sérios da nutrição de plantas, chegando a limitar o poder nutritivo de um meio de cultivo. A resposta das plantas varia de acordo com diversos fatores, como a cultivar e a espécie, a idade e o desenvolvimento vegetativo, as condições ambientais e as práticas de cultivo (SOUZA, 1995).

Para o cultivo de plantas cítricas em substrato livre de solo, não existem recomendações específicas referentes à salinidade, mas estudos com plantas ornamentais fornecem subsídios para a interpretação. Em geral, para a fase de sementeira, recomenda-se o uso de substratos com TTSS no máximo de $2 \mathrm{~g} \mathrm{~L}^{-1}$, a fim de evitar problemas futuros de excesso de salinidade (KÄMPF, 2000).

A salinidade do substrato mistura 1, antes do cultivo, pode ser considerada normal e a dos comerciais pode ser considerada alta, conforme os dados apresentados na tabela 2 (RÖBER \& SCHALLER, 1985).

Os resultados referentes aos teores de macronutrientes presentes na matéria seca da parte aérea estão apresentados na tabela 3 . A análise estatística não revelou interação significativa entre os substratos e os porta-enxertos para este parâmetro de avaliação. Para teores foliares da cultura de citros, os teores de nitrogênio presentes nesses porta-enxertos são considerados deficientes, os de fósforo satisfatórios, os de potássio de satisfatórios a altos, os de cálcio deficientes e os de magnésio de baixos a satisfatórios (COMISSÃO DE FERTILIDADE DO SOLO - RSE SC, 2000).

Apesar do substrato comercial 2 ter os maiores índices de nutrientes antes do cultivo, observase que houve acúmulo menor na matéria seca aérea, principalmente de $\mathrm{N}$ e K. Este fato, provavelmente, deveu-se à inibição da absorção de nutrientes por uma maior pressão osmótica causada pelo substrato, pois, segundo KÄMPF (2000), níveis de $3 \mathrm{~g} \mathrm{~L}^{-1}$ de sais no substrato podem ser considerados altos e, em alguns casos, fitotóxicos. Esses dados realçam a tese de especialistas de que quanto menor a adubação de base dos substratos, principalmente quando o método de propagação é por sementes, mais fácil é o manejo da adubação complementar, pois, em princípio, todos os porta-enxertos devem receber adubações complementares de nitrogênio.

Segundo os resultados do conteúdo nutricional no substrato antes do cultivo (Tabela 2), pode-se verificar que os níveis de todos os nutrientes são considerados altos; entretanto, observa-se que a absorção de cálcio, para todos os tratamentos, e a de magnésio, para o substrato comercial 1 e a mistura 1 e para o porta-enxerto limoeiro "Cravo" foram deficientes. Isto corrobora as afirmações de que existe um forte

Ciência Rural, v.36, n.6, nov-dez, 2006. 
antagonismo na absorção de potássio com cálcio e magnésio, pois parece impossível ter ao mesmo tempo níveis altos desses nutrientes nas plantas (MALAVOLTA\& VIOLANTENETO, 1989).

\section{CONCLUSÕES}

As características químicas dos substratos são determinantes para o desenvolvimento adequado dos porta-enxertos, sendo a salinidade elevada prejudicial. É possível produzir porta-enxertos, na fase de sementeira, com bom tamanho e desenvolvimento radicular, com 120 dias após a semeadura, sendo que os citranges "C13" e "C 37 " podem ser alternativas à diversificação.

\section{REFERÊNCIAS}

CARVALHO, S.A. de; SOUZA, M. de. Doses e freqüência de aplicação de nitrato de potássio no crescimento do limoeiro "Cravo" e da tangerineira "Cleópatra" em bandejas. Pesquisa Agropecuária Brasileira, Brasília, v.31, n.11, p.815-822, 1996.

CARVALHO, S.A. et al. Produção de material básico e propagação. In: MATTOS JÚNIOR, D. et al. Citros. Campinas: Instituto Agronômico e Fundag, 2005. Cap.10, p. 281-311.

COMISSÃO DE FERTILIDADE DO SOLO - RS e SC. Recomendações de adubação e de calagem para os estados do Rio Grande do Sul e de Santa Catarina. 3.ed. Passo Fundo: SBCS - Núcleo Regional Sul, 2000. 223p.

DE BOODT, M.; VERDONCK, O. The physical properties of the substrates in horticulture. Acta horticulturae, Wageningen, v.26, p.37-44, 1972 .

FERMINO, M.H. Aproveitamento de resíduos industriais e agrícolas como alternativas de substratos hortícolas. 1996. 90f. Dissertação (Mestrado em Fitotecnia) - Programa de Pós-graduação em Fitotecnia, Faculdade de Agronomia, Universidade Federal do Rio Grande do Sul.

HOFMANN, G. Verbindliche methoden zur untersuchung von TKS und gartnerischen erden. Mitteilungen der VSLUFA, Heft, v.6, p.129-153, 1970.
JOÃO, P.L. Procedimientos y problemática para la implantación de um programa de certificación de cítricos en el Estado de Rio Grande do Sul - Brasil. ValênciaEspanha: Universidade Politécnica de Valência - Instituto Valenciano de Investigaciones Agrarias, 1999. 97p.

KÄMPF, A.N. Produção comercial de plantas ornamentais. Guaíba: Agropecuária, 2000. 254p.

MALAVOLTA, E.; VIOLANTE NETTO, A. Nutrição mineral, calagem, gessagem e adubação dos citros Piracicaba: Associação Brasileira para Pesquisa da Potassa e do Fosfato. 1989. 153p.

MENEZES JÚNIOR, F.O.G.; FERNANDES, H.S. Substratos formulados com vermicomposto e comerciais na produção de mudas de couve-flor. Revista Brasileira de Agrociência, Pelotas, v.4, n.3, p.191-196, 1998

RÖBER, R.; SCHALLER, K. Pflanzenernährung im Gartenbau. Stuttgart: Ulmer, 1985. 352p.

SCHÄFER, G. Caracterização molecular, diagnóstico e avaliação de porta-enxertos na citricultura gaúcha. 2000. 81f. Dissertação (Mestrado em Fitotecnia) - Programa de Pósgraduação em Fitotecnia, Faculdade de Agronomia, Universidade Federal do Rio Grande do Sul.

SCHÄFER, G.; DORNELLES, A.L.C. Produção de mudas cítricas no Rio Grande do Sul - Diagnóstico da região produtora. Ciência Rural, Santa Maria, v.30, n.4, p.587-592, 2000

SCHMITZ, J.A.K. Cultivo de Poncirus trifoliata (L.) Raf. $\boldsymbol{e m}$ recepientes: influência de substratos e de fungos micorrízicos arbusculares. 1998. 144f. Dissertação (Mestrado em Fitotecnia). Programa de Pós-graduação em Fitotecnia, Faculdade de Agronomia, Universidade Federal do Rio Grande do Sul.

SOUZA, P.V.D. Optimización de la producción de plantones de cítricos en vivero. Inoculación com micorrizas vesiculares-arbusculares. 1995. 201f. Tese (Doutorado em Agronomia) - Escuela Técnica Superior de Inginieros Agrònomos, Universidad Politécnica de Valencia.

TEDESCO, M.J. et al. Análises de solo, plantas e outros materiais. 2.ed. Porto Alegre: Departamento de Solos da UFRGS, 1995. 174p. (Boletim Técnico de Solos, 5).

TEÓFILO SOBRINHO, J. Propagação dos citros. In: RODRIGUES, O. et al. Citricultura brasileira. Campinas: Fundação Cargill, 1991. V.1, p.281-301. 